\title{
CRIME ORGANIZADO TRANSNACIONAL E MISSÕES MILITARES: TENSÕES DA DIVISÃO INTERNO/EXTERNO NAS RELAÇÕES INTERNACIONAIS
}

\section{Transnational organized crime and military missions: tensions of the internal/external division in international relations}

\author{
David Succi Junior ${ }^{1}$ \\ Helena Salim de Castro ${ }^{2}$
}

\section{Introdução}

O estabelecimento das Relações Internacionais enquanto disciplina acadêmica fundamentou-se na oposição entre um âmbito doméstico pacificado, no qual a violência letal não constitui um instrumento legítimo de resolução de conflitos, e um sistema internacional anárquico, caracterizado por unidades políticas que se valem de seus instrumentos de força máxima para garantir a própria existência (BOBBIO, 2003; FREUND, 1995; WALTZ, 2002). Essa delimitação teórica entre o interno e o externo tem consequências diretas para a forma em que se compreende o uso da força e a definição da criminalidade.

Sob essa ótica, a polícia é entendida como o aparato do Estado destinado a atuar no interior de suas fronteiras, com a finalidade de garantir o cumprimento do sistema legal doméstico, através do uso mínimo da violência. As forças armadas, por sua vez, são entendidas como responsáveis por garantir a existência da unidade política, frente às suas homólogas, podendo, para tanto, valer-se da violência letal. Por outro lado, essa perspectiva pressupõe que o processo de construção do arcabouço jurídico interno, que define tanto aquilo que é ilegal, quanto os instrumentos para combatê-lo, está restrito ao plano doméstico (LÓPEZ, 2016; SAINT-PIERRE, 2011; WEISS, 2011).

O fenômeno do crime organizado transnacional, no entanto, coloca em questão a capacidade explicativa deste modelo teórico, uma vez que, por um lado, a definição daquilo que é ilegal está frequentemente inserida em processos internacionais de produção e disseminação de práticas e normas

\footnotetext{
${ }^{1}$ Doutorando e mestre pelo Programa de Pós-Graduação Relações Internacionais San Tiago Dantas (UNESP-UNICAMP-PUC-SP). Pesquisador do Grupo de Estudos de Defesa e Segurança Internacional (GEDES-UNESP). Email: david.succi.jr@gmail.com

${ }^{2}$ Professora de Relações Internacionais na Universidade Paulista (UNIP) .Doutoranda e mestre em Relações Internacionais pelo Programa de Pós-Graduação San Tiago Dantas (Unesp/Unicamp/Puc-Sp). Bacharel em Relações Internacionais pela Universidade Federal de Uberlândia (2014). Email: castrohelena281@gmail.com
} 
(BIGO, 2008). Por outro, as ações definidas como criminosas são recorrentemente reprimidas através da mobilização de forças militares no interior das fronteiras do Estado (REITANO; LUGO; JESPERSON, 2017). Neste artigo argumentamos que tanto a definição do crime quanto a escolha do aparato de força utilizado para lidar com o mesmo refletem processos políticos e sociais complexos que não se restringem a delimitações territoriais entre o doméstico e o internacional.

Desenvolvemos nosso argumento através da análise de dois fenômenos inter-relacionados. Por um lado, mostramos a forma na qual a agenda de segurança estadunidense da "guerra às drogas" influenciou a regulamentação e as práticas de repressão a essa atividade na América Latina. Por outro lado, analisamos a repressão ao tráfico de drogas ilícitas no Brasil, tanto do ponto de vista da definição legal da prática delitiva, que se aproxima da agenda proibicionista estadunidense, quanto a mobilização de forças armadas no interior das fronteiras nacionais. Mostramos que esta última constituiu uma característica histórica do país, mas que desde a década de 1990 esteve majoritariamente relacionada à repressão de grupos vinculados ao narcotráfico. Antes de nos dedicarmos à análise desses dois processos, explicitamos a concepção teórica tradicional na área de Relações Internacionais e a forma na qual é tensionada pela noção de crime organizado transnacional e certas políticas de repressão ao mesmo.

\section{Crime organizado transnacional e os instrumentos de força do Estado}

O modelo teórico sobre a organização política, constantemente absorvido e reproduzido sem contestações pelos acadêmicos da área de Relações Internacionais e de Estudos de Segurança Internacional, tem sido o ponto de partida para o desenvolvimento das agendas de pesquisa nestas áreas. Este consiste na ideia de que a constituição do Estado significou o estabelecimento de uma linha divisória territorial entre uma comunidade doméstica homogênea e o internacional. Ao espaço interno são atribuídas algumas características distintivas, sendo o monopólio legítimo da violência a principal (WEBER, 2002). Esse representaria, por um lado, a garantia de proteção dos membros da comunidade interna contra o livre uso da violência letal e, consequentemente, o medo da morte violenta. Por outro lado, seria o instrumento mais eficaz para garantir o cumprimento do conjunto de leis acordadas pela comunidade. Estaria assim fundado um espaço doméstico agonístico, no qual o uso da violência como instrumento de resolução de conflitos está descartado, sendo as disputas internas protagonizadas por adversários, submetidos a um mesmo conjunto de regras. Nesse sentido, o rechaço à violência como método de resolução de conflitos é a normativa fundante de uma comunidade política, no interior da qual um arcabouço mais amplo de leis é acordado entre seus membros e passa a regular suas relações (BOBBIO, 2003; FREUND, 1995; GIDDENS, 2008).

Consequentemente, aquele indivíduo cujo comportamento não se adequa às normas estabelecidas no interior de um Estado não se configura um adversário, uma vez que não está empreendendo uma disputa baseado no cumprimento de normas previamente acordadas, mas também não se configura como um inimigo a ser eliminado, por ser um cidadão nacional. É, então, um criminoso, “um 'desviante' que deve ser ajustado às normas de comportamento aceitável como o definido pelas obrigações da cidadania” (GIDDENS, 
2008, p. 205). De modo oposto, funda-se o internacional, espaço para o qual o Estado direciona seus instrumentos de máxima violência, por ser entendido como o espaço em que, não existindo um poder centralizado para garantir o funcionamento das normas, a força letal é sempre uma possibilidade, considerada em alguns casos legítima nas relações interestatais (ARON, 2002; MEARSHEIMER, 2001; WALTZ, 2002).

Para cada uma das responsabilidades do monopólio estatal do uso da força, como argumenta SaintPierre (2011; 2015), há um instrumento específico: a polícia, direcionada à coerção, tem como objetivo garantir o cumprimento do arcabouço jurídico interno, submetendo os criminosos ao sistema judiciário, mas, ainda assim, garantindo sua integridade física e moral; as forças armadas, por sua vez, são responsáveis por defender a existência do Estado diante de seus homólogos. É relevante indicar que o Estado não apenas monopoliza a violência no âmbito doméstico, mas também o faz internacionalmente, uma vez que deve controlar não apenas a violência que ocorre internamente, mas também aquela que é emanada a partir de seu território. Ainda que o internacional seja, sob esta ótica, compreendido como um âmbito incerto e ameaçador no qual o uso da força não foi eliminado como instrumento legítimo de resolução de conflitos, toda violência empreendida por atores não-estatais ou por agentes privados não chancelados por algum país é considerada ilegal. Em outras palavras, condena-se o uso da violência com fins privados (THOMPSON, 1994), como no caso das atividades do crime organizado transnacional.

O crime é tradicionalmente compreendido como a violação do conjunto de leis acordadas por uma comunidade política, isto é, no âmbito doméstico. Não obstante, a definição de crime, assim como o de Crime Organizado e Crime Organizado Transnacional, é tema de debate na literatura, em especial nas Relações Internacionais. Com efeito, Zabyelina (2009) assinala que as teorias mais tradicionais da área, realismo, institucionalismo liberal e construtivismo, apresentam perspectivas distintas sobre tais conceitos, mas que, de forma geral, nenhuma os explicam suficientemente, devido ao foco na ideia de soberania e controle estatal. A autora defende uma abordagem "pós-internacional", que reflita a lógica de interdependência do sistema internacional e cuja análise se baseie nas estruturas transnacionais das organizações criminais (ZABYELINA, 2009).

Antes de abordarmos a discussão sobre a transnacionalidade do crime, devemos analisar o termo “organizado". De acordo com Cepik e Borba (2011), o crime pode ser analisado por dois aspectos: a motivação e o dano causado. $\mathrm{O}$ ato de violar a lei pode conter uma motivação econômica (roubo ou tráfico de drogas) ou não (como no caso de homicídios sem roubo ou o crime de estupro), assim como, pode gerar um prejuízo direto ou difuso (quando não atinge um alvo específico). O crime organizado, para os autores, é, portanto, uma atividade ilegal, de caráter permanente, com motivação econômica e que promove um dano difuso nas sociedades (CEPIK; BORBA, 2011). Ao analisar os grupos criminosos, Cepik e Borba (2012, p. 378) conceituam o crime organizado como "coletivos que operam crimes regularmente (...) e que desenvolvem capacidades organizacionais, coercitivas, técnicas e políticas que são funcionais à execução desses crimes, sejam elas integrais ou parcialmente ilícitas". 
Para Marmo e Chazal (2016), o conceito de “crime organizado" remete à uma estrutura hierárquica de natureza controlada, a qual contradiz a realidade encontrada por muitas agências policiais: grupos organizados de forma horizontal e com fracas conexões. Para incorporar à análise grupos com estes tipos de dinâmica, as autoras utilizam o conceito de "crime transnacional". Tal conceito abarca os crimes que possuem dimensões transfronteiriças, assim como ocorre com as definições de "crimes domésticos" compreendidos como ilegais por leis nacionais e que podem ter um alcance transfronteiriço - e "crimes internacionais" - geram um prejuízo para toda a humanidade por violarem a lei criminal internacional. A diferença do conceito de "crime transnacional” com os demais, é que esse causa prejuízo a vários Estados e, mesmo não sendo considerados uma ofensa a toda a humanidade, constituem-se como um problema global (MARMO; CHAZAL, 2016). Segundo as autoras: "é convencional descrever crimes transnacionais como comportamento e atividades que têm um impacto negativo sobre os interesses de mais de um Estado-nação, implicando que esses tipos de crimes sempre ocorrem através das fronteiras e deveriam, consequentemente, serem tratados no nível internacional.” (MARMO; CHAZAL, 2016, p. 10, tradução própria).

Ao optar pelo conceito de "crime transnacional", as autoras consideram que utilização da denominação "crime organizado transnacional" poderia limitar o entendimento de pesquisadores sobre os crimes transnacionais. A referência ao termo “organizado" não permitiria uma observação da ampla gama de atividades ilegais cometidas por diferentes grupos (MARMO; CHAZAL, 2016). Não obstante, conforme observamos nos debates e instituições internacionais, foi o conceito de "crime organizado transnacional" que se disseminou e foi incorporado internacionalmente, como consequência de um processo de construção política do termo.

A definição de quais atividades violam a lei escrita, a priori, varia em cada país e localidade. Não obstante, observa-se na política mundial uma internacionalização e quase universalização de conceitos e definições. Pereira (2011) assinala que o conceito de crime é definido socialmente, sendo as unidades políticas soberanas responsáveis pela determinação das proibições, distinguindo o lícito do ilícito, e pelo estabelecimento de medidas de restrição e coerção às sociedades (PEREIRA, 2011, p. 40). De acordo com Edwards e Gill (2003, p. 3), os Estados Unidos podem ser considerados o "lar” do conceito e do fenômeno do crime organizado. No início do século $\mathrm{XX}$, o crime organizado era compreendido como uma "atividade sistemática” de grupos e indivíduos no país que extorquiam agentes policiais (PEREIRA, 2011). Foi a partir dos anos 1950, devido à forte presença de máfias italianas no país, que o crime organizado passou a ser considerado uma ameaça estrangeira (PEREIRA, 2015; WOODIWISS, 2003). O caráter transnacional do crime organizado começou a ser adotado, portanto, em detrimento da vinculação das atividades ilícitas com grupos estrangeiros e marginalizados.

Na década de 1990, o conceito de crime organizado transnacional (COT) ganhou impulso e passou a ser adotado em resoluções e convenções internacionais. Em setembro de 1994, foi realizada em Washington uma conferência sobre um novo entendimento global pluralista do crime organizado. A preocupação com o caráter transnacional das atividades criminosas gerou um ímpeto nas autoridades e agências estadunidenses em exigir o compartilhamento de informações entre policiais e oficiais de inteligências de diversos países. 
No mesmo ano, foi realizada a Conferência Ministerial Mundial sobre o Crime Organizado Transnacional, na Itália, sob o escopo das Nações Unidas. O teor das discussões e análises da Conferência foi semelhante àquele apresentado pelas autoridades dos Estados Unidos, reafirmando a capacidade de influência do país no delineamento da questão do crime (WOODIWISS, 2003).

Em 21 de outubro de 1995, o presidente estadunidense Bill Clinton instituiu uma diretiva presidencial, a Presidential Decision Directive 42 (PDD-42), que assinalou a ameaça do caráter transnacional da criminalidade (UNITED STATES, 1995). Com essa diretiva, o crime organizado transnacional foi alocado na agenda de segurança dos Estados Unidos e houve um grande ímpeto por apoio internacional na luta contra essa ameaça (PEREIRA, 2015). Como decorrência da PDD-42, em 1996, o governo dos Estados Unidos elaborou e apresentou, na Assembleia Geral da Organização das Nações Unidas (ONU), a Declaração das Nações Unidas Sobre o Crime e Segurança Pública, a fim de incentivar uma maior cooperação internacional para combater o crime organizado transnacional. A Declaração juntou-se à Comissão sobre Prevenção ao Crime e Justiça Criminal (CCPCJ), que havia sido criada em 1992, e, posteriormente, ao Escritório das Nações Unidas sobre Drogas e Crimes (UNODC), estabelecido em 1997 (PEREIRA, 2015). Esses órgãos conformam até os dias atuais o sistema das Nações Unidas para o enfrentamento do crime organizado transnacional.

A fim de convergir os debates e resoluções realizados anteriormente, foi estabelecida, no ano 2000, a Convenção das Nações Unidas Contra o Crime Organizado Transnacional. O documento elaborado assinala que o caráter transnacional das atividades criminosas ocorre quando: “a) for cometida em mais de um Estado; b) for cometida em um só Estado, mas uma parte substancial da sua preparação [...] tenha lugar em outro Estado; c) for cometida em um só Estado, mas envolva a participação de um grupo criminoso que pratique atividades criminosas em mais de um Estado; ou d) for cometida em um só Estado, mas produza efeitos substanciais noutro Estado" (NAÇÕES UNIDAS, 2000).

Há na literatura um debate sobre a intensificação do fenômeno do crime organizado transnacional. Alguns autores compartilham do entendimento de que o COT vivenciou um crescimento exponencial a partir dos anos 1990, como decorrência da globalização, uma vez que o desenvolvimento dos meios de transporte e comunicação gerou um maior fluxo de pessoas e mercadorias, tanto lícitas quanto ilícitas. Ademais, com os projetos neoliberais, característicos da década de 1990, que culminaram na privatização de empresas e maior liberdade de ação no mercado mundial, tornou-se mais difícil o controle das transações internacionais por parte dos governos (FRASCINO; CASTRO, 2017).

Cockayne (2007), afirma que, mesmo sendo uma preocupação antiga dos Estados, o crime organizado tem ocupado um papel central nos fóruns internacionais nas últimas décadas. O processo de globalização, que expandiu o alcance global dos meios de comunicação, das finanças e dos meios de transporte, intensificou e facilitou o transbordamento das atividades criminais (MARMO; CHAZAL, 2016). Além da significativa demanda internacional, as organizações criminosas têm-se beneficiado das novas dinâmicas mais fluidas da economia internacional e das diferenças legais entre as regulações nacionais, que contribuem para um contexto de diminuição da capacidade de controle estatal sobre os fenômenos 
transfronteiriços, tanto legais quanto ilegais (ZABYELINE, 2009). A interconexão entre tais fenômenos atinge diariamente a vida dos indivíduos ao redor do globo, como ocorre com o tráfico de drogas (MARMO; CHAZAL, 2016).

Por outro lado, criticando o foco atribuído ao pós-Guerra Fria como ponto chave para analisar o crime organizado transnacional, Andreas (2011) assinala que a globalização ilícita não é algo novo. Desde o período da mercantilização, com o comércio transoceânico e as restrições de mercadorias impostas pelas metrópoles, houve o desenvolvimento de trocas comerciais de caráter ilícito (ANDREAS, 2011). De acordo com o autor, “o crime organizado transnacional é, portanto, simplesmente um termo novo para uma antiga prática econômica”. (ANDREAS, 2011, p. 406). O que há de mais recente, na verdade, é a globalização do controle do crime. As próprias organizações e convenções que visam definir o conceito de crime organizado transnacional também se enveredam na construção de mecanismos conjuntos e internacionais para lidar com as atividade e grupos criminosos. A expansão das atividades de policiamento e os avanços tecnológicos dos mecanismos de vigilância e controle estatais contribuem para a transnacionalização do combate dos fluxos ilícitos (ANDREAS, 2011).

Diante da internacionalização e universalização dos conceitos e mecanismos de controle, compreende-se, portanto, que o fenômeno do crime organizado transnacional e as respostas ao mesmo retiram do âmbito estatal doméstico a exclusividade da definição da atividade criminosa. Ademais, do ponto de vista do uso da força, a resposta a essas atividades ilícitas tem sido acompanhada de uma série de fenômenos que contrastam a delimitação convencional entre forças armadas e polícia. Nesse sentido, podemos citar a utilização de técnicas e equipamento militar pelas forças policiais, o uso de técnicas e equipamento policiais pelas forças armadas, a atuação do instrumento militar em espaços e com funções convencionalmente policiais, o emprego das forças de segurança pública em âmbitos tradicionalmente militares e a atuação conjunta entre as duas agências, que são caracterizadas por um conjunto de autores como um processo de rompimento com a clara delimitação entre segurança interna e defesa externa (ANDREAS; PRICE, 2001; BIGO, 2016; KRASKA, 2007; LÓPEZ, 2016; SAINT-PIERRE, 2011).

A inadequação da perspectiva convencional sobre os instrumentos estatais de força acentua-se diante das especificidades latino-americanas. Com efeito, Pearce (2010) argumenta que a violência recorrente nos países da região não representa uma falha das estruturas estatais, mas reflete uma forma particular de Estado, cuja legitimidade não se sustenta no monopólio do uso da força, mas na ausência do mesmo. Deste modo, como a autora argumenta, o enfrentamento de grupos violentos internos constitui uma fonte de legitimidade para estes Estados. Para avançarmos nosso argumento, mostraremos como a agenda estadunidense influenciou a caracterização do narcotráfico como ameaça à segurança internacional e regional. Posteriormente analisaremos, de forma mais específica, o combate ao narcotráfico no Brasil.

\section{A construção da "guerra às drogas" nas Américas}

A experiência e a elaboração de uma agenda de segurança pelo governo dos Estados Unidos foram essenciais para a construção do que se conformou internacionalmente como crime organizado 
transnacional. O esforço desprendido pela grande potência na construção do crime organizado como uma ameaça influenciou as discussões regionais e globais sobre essa temática. Um dos maiores êxitos estadunidense no estabelecimento de uma agenda de segurança na América Latina foi a expansão da chamada "guerra às drogas" (FRASCINO; CASTRO, 2017). Iniciada a partir de um discurso do presidente Richard Nixon, em 1971, no qual afirmou que o abuso de drogas era o "inimigo público número um dos Estados Unidos” (NIXON, 1971), essa política antidrogas impulsionou uma série de instituições e instrumentos para o combate ao tráfico de entorpecentes.

Em 1974, foi criada a principal agência do país voltada para o controle e repressão da produção e comércio de drogas, a Drug Enforcement Administration (DEA). A DEA ampliou suas ações para outros territórios por meio do estabelecimento de escritórios nas grandes capitais latino-americanas a fim de garantir a manutenção de uma luta regional contra essa suposta nova ameaça. Ao longo da década de 1980, a política de "guerra às drogas" expandiu-se para a América Latina. O presidente Ronald Reagan estabeleceu, em 1986, uma nova Diretiva Nacional, denominada Narcotics and National Security, cujo objetivo foi aumentar a eficácia das ações de combate ao tráfico de drogas. Ademais, esse documento afirmava que era preciso uma atuação para além das fronteiras estadunidenses. Os países de origem das drogas eram considerados incapazes de combater, ou condescendentes com, os grupos traficantes, necessitando assim do apoio dos Estados Unidos (UNITED STATES, 1986).

Em paralelo a essa Diretiva, foi desenvolvido o mecanismo de certificação unilateral. Esse mecanismo consistia em um acordo entre o governo estadunidense e demais governos latino-americanos, estabelecendo que estes últimos deveriam apoiar as medidas antidrogas impostas pelos Estados Unidos para evitar a aplicação de sanções comerciais e econômicas (HERZ, 2002). A partir de então, uma série de políticas e instrumentos de ação foram despendidos na luta regional contra o tráfico de drogas, com a participação de governos e organismos multilaterais da América Latina.

Uma das primeiras operações antidrogas no continente, que contou com a atuação direta dos Estados Unidos, ocorreu em 1986 na Bolívia, a Operação Blast Furnace. O governo estadunidense enviou uma grande força tarefa, composta por soldados e técnicos militares norte-americanos, além da atuação da DEA, para liderar e apoiar as forças de segurança bolivianas com o objetivo de destruir laboratórios de refinamento da pasta base de cocaína, localizados no país (RODRIGUES, 2012a). Em 1989, no governo de George H. W. Bush (1989-1993), foram estabelecidas a National Security Directive de número 18, nomeada de International Counternarcotics Strategy e a National Drug Control Strategy, as quais reforçaram a política de proibição das drogas e a militarização do combate ao tráfico. Essas estratégias afirmavam a necessidade de atuação e assistência militar nos países da região andina (Bolívia, Colômbia e Peru), reforçando a percepção do tráfico de drogas como uma ameaça regional (RODRIGUES, 2012b). A Operação Causa Justa no Panamá, em 1989, pode ser compreendida enquanto consequência dessas Diretivas. Conhecida como o marco da guerra às drogas no continente, nessa operação treze mil fuzileiros da marinha estadunidense invadiram o país para capturar o então presidente Noriega, que havia sido acusado de envolvimento com o narcotráfico pela justiça dos Estados Unidos (VILLA, 2009; RODRIGUES, 2012a). 
O governo posterior, do presidente Bill Clinton (1993-2001), iniciou seu mandato com uma postura menos repressiva quanto ao combate ao abuso de drogas. Em 1994, por exemplo, realizou-se a primeira Cúpula das Américas, a qual resultou no "princípio da responsabilidade compartilhada", que afirmava a necessidade de um enfrentamento coletivo a essa ameaça que atingia a todos (RODRIGUES, 2012b). Não obstante, no final do governo Clinton, em 1999, foi elaborado um dos principais planos de combate ao tráfico de drogas do continente, o Plano Colômbia. Com a intenção de expandir o Plano Colômbia para outros países da região, como o Panamá e o Brasil, na administração de George W. Bush (2001-2009) foi criada, em 2001, a Iniciativa Regional Andina, denominada posteriormente de Iniciativa Andina Antidrogas (VILLA; OSTOS, 2005). No ano de 2007, os governos estadunidense e mexicano assinaram um acordo que deu origem à Iniciativa Mérida. Tal acordo propunha uma maior militarização do combate às organizações narcotraficantes no México. Dois anos depois, em 2009, durante o governo de Barack Obama, foi implementada a Iniciativa Mérida II, ou Beyond Merida, que, não apenas manteve o caráter repressivo da proposta anterior, como também buscou ampliá-lo em alguma medida, principalmente ao assinalar a necessidade de construção de “comunidades fortes e resilientes” (RODRIGUES, 2012b; LYRA, 2004, p.69).

Para além dessas iniciativas bilaterais, a consolidação da "guerra às drogas" na América Latina foi possível graças ao desenvolvimento de organismos multilaterais. O principal organismo responsável por incentivar as discussões e a implementação de medidas para romper com o tráfico na região foi a Organização dos Estados Americanos (OEA), tendo os Estados Unidos como principal liderança. No âmbito da OEA, foi criada a Comissão Interamericana para o Controle do Abuso de Drogas (CICAD). Com a sua Primeira Sessão Ordinária realizada em abril de 1987, em Washington, a CICAD instituiu-se como um foro de coordenação política entre os países do hemisfério, a fim de incentivar a cooperação nos níveis bilateral e multilateral (SILVA, 2013).

Apesar da importância e diversos avanços promovidos pela CICAD, permaneciam algumas críticas sobre seu funcionamento, em especial no que concerne à influência direta dos Estados Unidos. Em resposta às críticas, foi desenvolvido outro organismo multilateral no hemisfério para lidar com a ameaça das drogas. Restrito a um âmbito sub-regional, os países independentes da América do Sul criaram, em 2010, o Conselho Sul-Americano para o Problema Mundial das Drogas (CSPMD), organismo setorial pertencente ao quadro geral da União das Nações Sul-Americanas (Unasul). O CSPMD pretendia, em sua origem, impulsionar políticas de combate ao consumo e comércio de drogas que se desvinculassem das medidas orientadas pela repressão. Os países membros do Conselho deveriam dividir-se em grupos de trabalho para executar as diversas atividades dos Planos de Ação, os quais abarcavam desde a necessidade de redução da oferta de drogas, até ações de redução da demanda e o combate de lavagem de ativos. De maneira geral, o objetivo era garantir a eficácia do controle das drogas na região a partir da troca de informações e a cooperação entre os países membros (CASTRO, 2016). Em fevereiro de 2018, foi realizada a VI reunião do CSPMD, na cidade de Buenos Aires (Argentina), em que o foco foi tentar estabelecer uma agenda de trabalho para o biênio 2018-2019, voltada, principalmente, para a realização de seminários e informes sobre várias 
áreas temáticas como a redução da oferta e da demanda, saúde, direitos humanos, gênero, desenvolvimento alternativo, entre outros (UNASUR, 2018).

Do ponto de vista das missões militares, o conceito de ameaça multidimensional, que se conformou no âmbito da OEA, produziu uma agenda de segurança que insere o crime organizado transnacional em um amplo conjunto de fenômenos de diversas naturezas e origens, que requerem diferentes respostas, como terrorismo, corrupção, ataques cibernéticos, pobreza extrema, deterioração do meio ambiente e riscos à saúde (ORGANIZAÇÃO DOS ESTADOS AMERICANOS, 2003). Saint-Pierre (2012), considera que essa agenda de segurança contempla o interesse estadunidense de manter a atenção dos militares latino-americanos voltada para questões domésticas, como havia acontecido durante a Guerra Fria (LÓPEZ, 1987). A concepção da multidimensionalidade da segurança e da ameaça repetiu-se nas Conferências de Ministros de Defesa das Américas, âmbito no qual os responsáveis pelas pastas de defesa e, portanto, das forças armadas dos países da região, eram chamados a debater questões que transcendem suas competências internas, como segurança interna, saúde pública e desenvolvimento.

Por outro lado, no âmbito da Unasul houve uma clara distinção institucional entre as questões de defesa, crime organizado transnacional e drogas ilícitas. O debate relativo à defesa e, portanto, às funções militares ficaram restritas ao Conselho de Defesa Sul-Americano (CDS), enquanto as questões de criminalidade transnacional foram delegadas ao Conselho Sul-Americano em Matéria de Segurança Cidadã, Justiça e Coordenação de Ações contra a Delinquência Organizada Transnacional (CSSCJDOT) e, como já citamos, os problemas vinculados às drogas ilícitas estão circunscritos no âmbito do CSPMD.

Além da divisão estrutural, a clara diferenciação entre as questões de defesa, operacionalizadas pelas forças armadas, e de segurança pública, cujo instrumento são as forças policiais, ficou explícito em relatório do Centro de Estudos Estratégicos de Defesa (CEED), órgão permanente do CDS, segundo o qual não cabe a este conselho tratar de políticas de segurança pública, uma vez que esta não está no escopo dos ministérios de defesa (UNIÓN DE LAS NACIONES SURAMERICANAS, 2012). No âmbito da CSSCJDOT, por outro lado, as respostas aos problemas de segurança pública vinculados ao crime organizado transnacional não se baseiam no instrumento militar, mas na cooperação policial, que prevê mecanismos de troca de informações, procedimentos compartilhados, cooperação em ações operativas e de investigação e assistência técnica. Mesma linha de ação que se observa com os Planos de Ação estabelecidos pelo CSPMD. Ademais, parte dos objetivos do CSSCJDOT não se restringem à repressão do crime organizado, abrangendo também questões vinculadas à garantia dos direitos humanos como violência intrafamiliar, contra a mulher e comunidade LGBT, além do fortalecimento de um sistema de assistência jurídica gratuita nos Estadosmembros (VIGGIANO, 2018).

Apesar da relevância política de uma organização regional em que não apenas o problema das drogas e do crime organizado transnacional são discutidos na ausência dos Estados Unidos, mas na qual se estabeleceu uma agenda divergente daquela vinculada à perspectiva estadunidense pautada na repressão, devemos destacar as críticas à fraca efetivação das políticas propostas no âmbito do CSPMD e do CSSCJDOT, principalmente considerando o aumento e avanço da violência e do crime na região (FERREIRA, 2017). Por 
abordarem temáticas sensíveis e complexas para os governos, há uma dificuldade na obtenção e compartilhamento de informações, não somente entre os países, mas também com a sociedade civil. Viggiano (2018) assinala ainda a diferença entre os cargos e níveis dos representantes enviados pelos Estados-Membros (há desde representantes vinculados ao Ministério da Justiça, até aqueles vindo dos Ministérios da Defesa), o que dificulta o diálogo. Autora destaca ainda a ausência de participação de atores não-governamentais nas discussões e projetos do CSSCJDOT, como um dos principais desafios desse mecanismo. No que concerne a questão das drogas, podemos considerar como desafio a dificuldade de harmonização entre as legislações (FERREIRA, 2017). As políticas antidrogas são distintas entre os países da região, como no caso da recente legalização do uso recreativo da maconha no Uruguai em oposição à manutenção, e até recrudescimento, de uma abordagem proibitiva e repressiva no Brasil.

Ademais, em ambos os Conselhos há um número reduzido de reuniões e pouco aprofundamento nos projetos - a maioria das atividades realizadas são seminários e debates, em comparação ao pequeno número de políticas concretas. Deve-se pontuar ainda, que o funcionamento da Unasul está comprometido. Além de se encontrar sem um Secretário-Geral, desde 2017, quando Ernesto Samper deixou o cargo, a organização encontra-se em dificuldades financeiras e a maior parte de seus conselhos não realiza reuniões há anos. Em 2018, Argentina, Brasil, Chile, Colômbia e Peru suspenderam sua participação no bloco. Em 2019, o governo equatoriano também se retirou e pediu a devolução do prédio que é sede da organização (JAEGER, 2019).

\section{O combate ao tráfico de drogas no Brasil e o emprego interno das forças armadas}

Para sustentar o argumento de que a distinção entre legalidade e ilegalidade - assim como a escolha entre o instrumento policial e o militar para lidar com determinada questão - reflete escolhas políticas e processos históricos complexos, que não se restringem à divisão estática entre o doméstico e o internacional, nesta seção apresentamos um breve panorama do desenvolvimento da criminalização das drogas no Brasil e da constante atuação doméstica das forças armadas deste país.

O consumo e o tráfico de drogas são preocupações antigas da sociedade e governo brasileiros. Nos anos 1970, paralelamente ao início da guerra às drogas nas Américas, tais aspectos ganharam espaço na agenda de segurança nacional. Duas leis importantes nesse período foram a de $\mathrm{n}^{0} 5.726 / 71$ e a Lei de Tóxicos de 1976, que destacavam a necessidade de maior atenção do governo às ameaças das drogas e o desenvolvimento de políticas para a prevenção do uso de substâncias ilícitas (RODRIGUES, 2004). Não obstante, foi ao longo da década de 1990 que houve um aumento da repressão ao consumo e tráfico de drogas. Em 1990, o tráfico de entorpecentes passou a ser considerado um crime hediondo pela lei brasileira (RODRIGUES, 2012b) e o Departamento da Polícia Federal (DPF) e o Conselho Federal de Entorpecentes (CONFEN), criado em 1980, eram as principais instituições responsáveis pelo controle e repressão ao tráfico no país no período.

O início do século XXI marca a intensa participação do Brasil nos mecanismos regionais antidrogas. O governo brasileiro adotou uma postura ativa com relação à CICAD (SILVA, 2013), assim como estabeleceu-se como membro do Conselho Sul-Americano sobre o Problema Mundial das Drogas (CSPMD), 
apesar de não ter assumido a liderança em nenhum plano de ação deste organismo. Paralelamente, os anos 2000 caracterizam-se pelo desenvolvimento de leis e políticas nacionais voltadas para a prevenção e repressão às drogas. Em 2002, foi estabelecido o Observatório Brasileiro de Informações sobre Drogas (OBID), instituição responsável pela organização e compilação de informações sobre o problema das drogas no país (SILVA, 2013). Em 2005, foi aprovada a nova Política Nacional sobre Drogas (PNAD). No ano seguinte, em 2006, foi criado o Sistema Nacional de Políticas Públicas sobre Drogas (Sisnad). No artigo primeiro da lei que o estabelece (11.343/06) está determinado que o Sisnad "prescreve medidas para prevenção do uso indevido, atenção e reinserção social de usuários e dependentes de drogas; estabelece normas para repressão à produção não autorizada e ao tráfico ilícito de drogas e define crimes”.

Recentemente, em abril de 2019, o presidente da República, Jair Bolsonaro, estabeleceu o Decreto $\mathrm{N}^{\circ}$ 9.761, que instituiu algumas mudanças na Política Nacional de Drogas. As mudanças mais expressivas referem-se à substituição de uma abordagem de recuperação de danos pelo fortalecimento da política de internação forçada de usuários e aos mecanismos de diferenciação entre usuários e traficantes, os quais devem considerar, de acordo com o novo texto, "a quantidade da substância apreendida [critério presente na PND anterior], o local e as condições em que se desenvolveu a ação de apreensão, as circunstâncias sociais e pessoais e a conduta e os antecedentes do agente.” (BRASIL, 2019).

Esse conjunto de políticas e normativas expressa o caráter proibitivo da legislação antidrogas do Brasil, a qual conta com um aparato coercitivo e repressivo para garantir sua aplicabilidade. A Constituição Federal brasileira, no seu artigo 144, assinala que é de responsabilidade da Polícia Federal (PF) a prevenção e repressão ao tráfico de ilícitos (BRASIL, 2016). Diante da necessidade de promover uma cooperação nacional na luta antidrogas, a PF atua, recorrentemente, de forma conjunta com a Polícia Federal Rodoviária e as polícias militares e civis das unidades federativas do país. Não obstante, além das forças policiais, as forças armadas têm ampliado a sua participação nas tarefas de combate às drogas. Exército, Marinha e Força Aérea do Brasil compõem e ampliam o aparato repressivo estatal, atuando, inclusive, em operações antidrogas no âmbito doméstico; fortalecendo, assim, a "guerra às drogas" no Brasil.

A atuação interna das forças armadas brasileiras, que passou, principalmente a partir da década de 1990, a ser associada com a repressão ao tráfico de drogas, especialmente na cidade do Rio de Janeiro, não é um ineditismo na história do país. Os militares brasileiros foram, ao longo da história, constantemente mobilizados no interior das fronteiras nacionais. Tais intervenções estão diretamente vinculadas ao papel de garantidores da ordem, que se cristalizou enquanto função, como indicado por Mathias e Guzzi (2010), na quase totalidade das constituições nacionais, estando ausente apenas nas cartas constitucionais de 1824, no Império, e na de 1937. Durante o império no Brasil, as forças armadas foram mobilizadas na contenção de uma série de revoltas internas. Ademais, deve-se indicar que a instituição castrense teve participação direta na queda do Império e da República Velha, além de ter dado base à ditadura do Estado Novo e à destituição de Getúlio Vargas, em 1945 (McCANN, 2007; SOUZA, 2017).

Em 1964, os militares, por meio de um golpe de Estado, instituíram um governo autoritário no país, que durou até 1985. Nesse período, as forças armadas estiveram intensamente engajadas na repressão 
política no âmbito doméstico (ROUQUIÉ, 1984). A transição do regime autoritário para a democracia no Brasil foi caracterizada pelo intenso controle com o qual os militares levaram a cabo a própria saída do centro do poder político, com o objetivo de prevenir as consequências de um possível colapso do governo. Nesse sentido, a participação das forças armadas em assuntos internos não se tornou uma questão as ser debatida no país, como ocorreu durante com o fim do regime militar argentino (MATHIAS, 1995; OLIVEIRA, 1994; SOARES, 2006).

A Constituição de 1988, marco do estabelecimento da democracia no Brasil, manteve em seu artigo 142 a garantia da lei e da ordem (GLO) como uma das funções das forças armadas, juntamente com a defesa nacional e a garantia dos poderes constitucionais. O que se observou a partir de então foi uma série de legislações infraconstitucionais visando regulamentar essa atribuição militar, que passou cada vez mais a ser direcionada à repressão do tráfico de drogas ilícitas. A primeira foi a Lei Complementar 69 de 1991, que restringiu a definição constitucional acerca de quais poderes poderiam requisitar a atuação castrense no interior das fronteiras nacionais, limitando essa prerrogativa ao presidente da República. A regulamentação foi estabelecida após um juiz ter decretado a mobilização do Exército para reprimir a greve na Companhia Siderúrgica Nacional, em 1988 (OLIVEIRA, 1994). A primeira norma foi substituída pela Lei Complementar 97 de 1999, a qual determinou que a atuação militar nesse tipo de operação deve ocorrer quando os instrumentos destinados à segurança pública forem considerados esgotados.

Em 2001, o Decreto 3897 fixou as diretrizes para o planejamento, coordenação e execução das operações de GLO. A norma estabeleceu que na hipótese de alocação das forças armadas para a garantia da lei e da ordem, as mesmas serão incumbidas de executar tarefas de polícia ostensiva, atividades de repressão e prevenção. Determina ainda que as operações GLO devem ocorrer de modo episódico, com área e tempo de atuação limitados e previamente definidos. Em 2004, a Lei Complementar 117 alterou a norma de 1999 e definiu que os mecanismos de segurança públicos são considerados esgotados quando o chefe do Executivo Federal ou Estadual reconhece formalmente a indisponibilidade, inexistência ou insuficiência dos mesmos, o que abre espaço para a atuação das forças armadas. Nesse mesmo ano, através do Decreto $\mathrm{n}^{\circ}$ 5.144, foi criada o que ficou conhecida como Lei do Abate. De acordo com o estabelecido no decreto, a Força Aérea Brasileira poderia atacar aeronaves que sobrevoassem o espaço aéreo brasileiro sem identificação, após a autorização do presidente da república. Essa lei voltou-se principalmente para a apreensão de aeronaves suspeitas de tráfico de drogas.

Assim, de janeiro de 1992 a agosto de 2018, foram realizadas 133 operações de GLO no país (BRASIL, 2018). Nos anos de 1990, podemos destacar a operação de segurança da Conferência das Nações Unidas sobre o Meio Ambiente e o Desenvolvimento (ECO-92), que segundo Soares (2006) fortaleceu a figura dos militares como instrumentos de segurança pública no Rio de Janeiro. Entre 1994 e 1995 foi desenvolvida a Operação Rio, conjunto de ações militares visando combater o narcotráfico na cidade, que contou com o envolvimento direto e indireto de setenta e um mil soldados. No sertão nordestino houve uma série de operações das forças armadas entre 1995 e 1999, visando também reprimir práticas ilegais vinculadas ao tráfico de narcóticos (SOARES, 2006; ZAVERUCCHA, 2005). 
Nos anos 2000 nota-se a intensificação destas ações, assim como a progressiva institucionalização das mesmas. Em 2005, foi estabelecido na cidade de Campinas, no estado de São Paulo, o Centro de Instrução de Operações de Garantia da Lei e da Ordem, subordinado à $11^{\text {a }}$ Brigada de Infantaria Leve, destinado ao adestramento e produção de doutrina militar voltada à atuação em operações de GLO. Em 2006, operações das forças armadas visando recuperar armamentos roubados por grupos criminosos ocuparam doze favelas no Rio de Janeiro. No ano seguinte, houve a ocupação do morro da Providência, cujo encerramento foi decretado em 2008 quando onze militares foram acusados de entregar jovens a criminosos da comunidade rival (SUCCI JUNIOR, 2018).

$\mathrm{O}$ ano de 2010 configura-se como um ponto importante no processo aqui descrito. No mês de agosto foi estabelecida a Lei Complementar $\mathrm{n}^{\circ} 136$, a qual deu a prerrogativa para que as três forças militares brasileiras (exército, marinha e aeronáutica) tivessem poder de polícia para o combate ao tráfico de drogas nas regiões de fronteira. $\mathrm{O}$ artigo 16 da Lei $\mathrm{n}^{\circ}$ 136/10 determina que:

(...) cabe às Forças Armadas, além de outras ações pertinentes, também como atribuições subsidiárias, preservadas as competências exclusivas das polícias judiciárias, atuar, por meio de ações preventivas e repressivas, na faixa de fronteira terrestre, no mar e nas águas interiores, independentemente da posse, da propriedade, da finalidade ou de qualquer gravame que sobre ela recaia, contra delitos transfronteiriços e ambientais, isoladamente ou em coordenação com outros órgãos do Poder Executivo (BRASIL, 2010).

Neste mesmo ano houve grandes operações conjuntas entre polícias civil, militar e federal e forças armadas na cidade do Rio de Janeiro. Na ocasião, foi criada a Força de Pacificação, que ocupou os complexos de favelas do Alemão e da Penha e passou a atuar em questões que vão além do tráfico de drogas ilícitas, como o mercado ilegal de botijões de gás e de ligações clandestinas de televisão. Em 31 de março de 2014, a recém-eleita presidente, Dilma Rousseff, autorizou uma nova operação para garantia a lei e da ordem no Complexo da Maré, com vistas a garantir a segurança da cidade durante Copa do Mundo de Futebol, que seria realizada entre junho e julho de 2014. A partir de então, empregou-se as forças armadas em uma série de operações destinadas à ocupação das comunidades e implantação das Unidades de Polícia Pacificadora (UPP) (MATHIAS; CAMPOS; SANTOS, 2016; PASSOS, 2018). No ano anterior, o Ministério da Defesa havia publicado um documento, que foi reeditado em 2014, com o objetivo estabelecer orientações para o planejamento e emprego das forças armadas nas ações de GLO, o Manual de Operações para a Garantia da Lei e da Ordem (BRASIL, 2013; 2014).

A mobilização de tropas no interior das fronteiras nacionais para cumprir missões que envolvem o emprego da força marcou também a gestão de Michel Temer. Apesar de o seu primeiro ministro da Defesa, Raul Jungmann, no início da gestão ter denunciado o que chamou de banalização do uso das Forças Armadas em segurança pública, o ministro logo assumiu uma posição proeminente nas declarações sobre a segurança do Rio de Janeiro nos noticiários, relegando ao segundo plano o ministro da Justiça, Torquato Jardim (GARCIA, 2017). A título de exemplo, pode-se citar, entre outros casos, o emprego dos militares no estado do Espírito Santo, diante da greve da Polícia Militar (CAMPOS, 2017); em varreduras de presídios (DELGADO, 2017); em operações de segurança pública na região metropolitana de Natal (BENITES, 2017); e 
em diversas ações na cidade do Rio de Janeiro, culminando na intervenção federal em segurança pública no estado (BETIM, 2018). Ademais, em outubro de 2017, diante de pressões das forças armadas, envolvidas nesta intervenção, foi sancionada a Lei 13.491, segundo a qual os militares que venham a cometer crimes dolosos contra a vida não devem ser julgados pela justiça comum, mas por uma Corte Militar.

Podemos notar, portanto, que o direcionamento das forças armadas brasileiras para o interior das fronteiras nacionais é uma característica recorrente na história do país, cujas especificidades variam de acordo com o grupo conjunturalmente definido como inimigo interno. Em relação às especificidades conjunturais, destaca-se, visto o objeto aqui analisado, que as transformações legais vinculadas ao uso do instrumento militar, que foram empreendidas após a redemocratização, estiveram centradas majoritariamente na resposta ao crime organizado vinculado ao tráfico de drogas ilícitas. Deste modo, foi a preocupação com o combate a esta atividade ilícita específica que moldou a institucionalização de uma maior permissividade em relação ao uso doméstico do instrumento militar.

\section{Considerações finais}

Como debatemos ao longo do artigo e evidenciamos com o caso do combate ao tráfico de drogas no Brasil, pensar o crime organizado transnacional em suas diversas facetas e o tipo de força empregada para lidar com o mesmo requer a compreensão mais profunda dos processos sociais e políticos que definem e redefinem as atividades consideradas criminosas e os métodos considerados adequados para lidar com as mesmas. Discorremos sobre a dificuldade de compreender o crime organizado transnacional, e a resposta ao mesmo, com base em uma divisão estática entre interno e externo, que concebe as relações internacionais a partir de unidades políticas territorialmente definidas e mutuamente excludentes. Conforme observado na condução da "guerra às drogas" na América Latina e, mais especificamente, no caso do Brasil, o processo de definição jurídica do crime não se limita à territorialidade do Estado, uma vez que a capacidade de influência de determinados governos e países permite a universalização e institucionalização de normas e regras. De forma correlata, a definição do tipo de força empregada para responder ao crime transnacional não pode ser compreendida pela localização doméstica ou internacional dos grupos criminosos. Isto porque, por um lado, as atividades ilícitas transcendem as delimitações territoriais de um Estado e, por outro, é crescente a cooperação internacional entre agências de segurança, além de a atuação militar no âmbito doméstico ser recorrente na história de muitos países. Desta forma, o modelo teórico que associa forças militares ao âmbito internacional e policiais ao doméstico representa mais um princípio normativo do que uma descrição da forma em que o uso da força é organizado.

\section{REFERÊNCIAS}

ANDREAS, P.; PRICE, R. From War Fighting to Crime Fighting: Transforming the American National Security State. International Studies Review, v. 3, n. 3, p. 31-52, 2001.

ANDREAS, Peter. Illicit globalization: myths, misconceptions, and historical lessons. Political Science Quarterly, v. 126, n. 3, p. 403-425, 2011. 
ARON, R. Paz e Guerra entre as nações. Brasília: Editora Universidade de Brasília, 2002.

BENITES, Afonso. Temer anuncia envio militares para conter violência em Natal. El País, Jan. 2017. Disponível em <https://brasil.elpais.com/brasil/2017/01/19/politica/1484848066_982240.html?rel=mas〉. Acesso: 14 out. 2018.

BETIM, Felipe. Intervenção federal no Rio decretada por Temer abre inédito e incerto capítulo. El País, Fev. $2018 . \quad$ Disponível em <https://brasil.elpais.com/brasil/2018/02/16/politica/1518803598_360807.html>. Acesso: 14 out. 2018.

BIGO, D. Globalized (in)security: The field and the ban-opticon. In: BIGO, D.; TSOUKALA, A. (Eds.). . Terror, Insecurity and Liberty: Illiberal practices of liberal regimes after 9/11. New York: Routledge, 2008. p. 10-48.

BIGO, D. Rethinking security at the crossroad of international relations and criminology. British Journal of Criminology, v. 56, p. 1068-1086, 2016.

BOBBIO, N. Relações Internacionais. In: O filósofo e a política: antologia. Rio de Janeiro: Contraponto, 2003. p. 317-382.

BRASIL. Constituição da República Federativa do Brasil. Brasília, DF: Câmara dos Deputados: Centro de Documentação e Informação, 2016, 124p. Disponível em <http://www2.camara.leg.br/atividadelegislativa/legislacao/Constituicoes_Brasileiras/constituicao1988.html/ConstituicaoTextoAtualiza do_EC92.pdf>. Acesso em 5 jul. 2016.

BRASIL Decreto $\mathbf{N}^{\circ} \mathbf{5 . 1 4 4}$, de 16 de julho de 2004. Regulamenta os $\S \S 1^{\circ}$, $2^{\circ}$ e $3^{\circ}$ do art. 303 da Lei ํo 7.565 , de 19 de dezembro de 1986, que dispõe sobre o Código Brasileiro de Aeronáutica, no que concerne às aeronaves hostis ou suspeitas de tráfico de substâncias entorpecentes e drogas afins. Diário Oficial da União, Brasília, DF, 16 de jul. 2004a. Disponível em <http://www.planalto.gov.br/ccivil_03/_ato2004-2006/2004/decreto/d5144.htm>. Acesso em 5 jul. 2016.

BRASIL. Decreto No 9.761, de 11 de abril de 2019. Aprova a Política Nacional sobre Drogas. Diário Oficial da União, Brasília, DF, 11 abr. 2019. Disponível em <http://www.planalto.gov.br/ccivil_03/_ato2019-2022/2019/decreto/D9761.htm>. Acesso em 17 mai. 2019.

BRASIL. Lei Complementar $\mathrm{n}^{\circ} 69$ de 23 de julho de 1991. Dispõe sobre as normas gerais para a organização, o preparo e o emprego das Forças Armadas. Disponível em <https://www2.camara.leg.br/legin/fed/leicom/1991/leicomplementar-69-23-julho-1991-364952publicacaooriginal-1-pl.html>. Acesso em 31 jul. 2019.

BRASIL. Lei Complementar $n^{\circ} 97$ de junho de 1999. Dispõe sobre as normas gerais para a organização, preparo e o emprego das Forças Armadas. Disponível em <http://www.planalto.gov.br/ccivil_03/leis/LCP/Lcp97.htm>. Acesso em 26 abr. 2017.

BRASIL. Lei Complementar $\mathbf{n}^{\circ} 117$ de setembro de 2004. Altera a Lei Complementar no 97, de 9 de junho de 1999, que dispõe sobre as normas gerais para a organização, o preparo e o emprego das Forças Armadas, para estabelecer novas atribuições subsidiárias. Disponível em <http://www.planalto.gov.br/ccivil_03/leis/LCP/Lcp117.htm>. Acesso em 26 abr. 2017.

BRASIL. Lei Complementar $\mathbf{n}^{\circ} 136$ de agosto de 2010. Altera a Lei Complementar no 97, de 9 de junho de 1999, que "dispõe sobre as normas gerais para a organização, o preparo e o emprego das Forças Armadas”, para criar o Estado-Maior Conjunto das Forças Armadas e disciplinar as atribuições do $\begin{array}{llllll}\text { Ministro de } & \text { Estado da } & \text { Defesa. } & \text { Disponível }\end{array}$ 
<http://www.planalto.gov.br/ccivil_03/leis/lcp/lcp136.htm_. Acesso em 26 abr. 2017.

BRASIL. Lei 13.491 de outubo de 2017. Altera o Decreto-Lei no 1.001, de 21 de outubro de 1969 - Código Penal Militar. Disponível em <http://www.planalto.gov.br/ccivil_03/_ato20152018/2017/lei/l13491.htm>. Acesso em 14 out. 2018.

BRASIL. Ministério da Defesa. CHEFIA DE OPERAÇÕES CONJUNTAS. Histórico de GLO. 2018. Disponível em

$<$ https://www.defesa.gov.br/arquivos/exercicios_e_operacoes/glo/13092018/2_tabelas_glo_atualiza da_em_13_SET_18.pdf $>$. Acesso em 14 out. 2018.

BRASIL. Ministério da Defesa. Garantia da Lei e da Ordem. 2013. Disponível em: <https://www.defesa.gov.br/arquivos/File/doutrinamilitar/listadepublicacoesEMD/md33.pdf>. Acesso em 21 abr. 2017.

BRASIL. Ministério da Defesa. Garantia da Lei e da Ordem. 2014. Disponível em: <https://www.defesa.gov.br/arquivos/2014/mes02/md33_m_10_glo_2ed_2014.pdf> Acesso em 21 abr. 2017.

CAMPOS, Ana C. Espírito Santo transfere controle de segurança pública para as Forças Armadas. Agência Brasil, fev. 2017. Disponível em <http://agenciabrasil.ebc.com.br/geral/noticia/2017-02/espiritosanto-transfere-controle-da-seguranca-publica-para-forcas-armadas>. Acesso em 14 out. 2018.

CASTRO, H. S. O processo de socialização do Conselho Sul-americano sobre o Problema Mundial das Drogas. Conjuntura internacional, v. 13, n. 2, p. 56-67, 16 dez. 2016. Disponível em: <http://periodicos.pucminas.br/index.php/conjuntura/article/view/11586>. Acesso em $20 \mathrm{dez}$. 2016.

CEPIK, Marco; BORBA, Pedro. Crime organizado, estado e segurança internacional. Contexto internacional. Rio de Janeiro, v. 33, n. 2, p. 375-405.

COCKAYNE, James. Transnational Organized Crime: Multilateral Responses to a Rising Threat. Coping with Crisis - Working Paper Series, Abril 2007.

DELGADO, Malu. Militares nos presídios "é mais marketing do que solução". Deutsche Welle, Jan. 2017. Disponível em <https:/www.dw.com/pt-br/militares-nos-pres\%C3\%ADdios-\%C3\%A9-maismarketing-do-que-solu\%C3\%A7\%C3\%A3o/a-37184648>. Acesso em 14 out 2018.

DIAMINT, R. A New Militarism in Latin America. Journal od Democracy, v. 26, n. 4, p. 155-168, 2015.

EDMUNDS, T. What are armed forces for? The changing nature of military roles in Europe. International Affairs, v. 82, n. 6, p. 1050-1075, 2006.

FERREIRA, M. A. S. V. Criminality and Violence in South America: The Challenges for Peace and UNASUR's Response. International Studies Perspectives, v. 18, p. 64-80, 2017.

FRASCINO, Priscila V.; CASTRO, Helena S. A Globalização Envolve uma Dimensão de Segurança? O Crime e Policiamento Transnacional. In: MOITA, Luís; PINTO, Luís Valença (Coord.). Espaços económicos e espaços de segurança. Lisboa: UAL; OBSERVARE, 2017. P. 133-158.

FREUND, Julien. Sociología del conflicto. [s.l.]: Ministerio de Defensa de España, Secretaría General Técnica, 1995.

GARCIA, Gustavo. Ministro diz que há 'banalização' do uso das Forças Armadas na segurança pública. G1, jun. 2017. Disponível em <https://g1.globo.com/politica/noticia/ministro-diz-que-ha-banalizacaodo-uso-das-forcas-armadas-na-seguranca-publica.ghtml>. Acesso em 14 out 2018. 
GIDDENS, A. O Estado-Nação e a Violência. São Paulo: Editora da Universidade de São Paulo, 2008.

GRAHAM, S. Cidades sitiadas: o novo urbanismo militar. São Paulo: Boitempo, 2017.

GUITTET, E.-P. Military activities within national boundaries: the French case. In: BIGO, D.; TSOUKALA, A. (org.). Terror, Insecurity and Liberty: Illiberal practices of liberal regimes after 9/11. New York: Routledge, 2008. p. 121-145.

HARIG, C. Synergy effects between MINUSTAH and public security in Brazil. BRASILIANA- Journal for Brazilian Studies, v. 3, n. 2, p. 142-168, 2015.

HEAD, M.; SCOTT, M. Domestic Deployment of the Armed Forces: Military Powers, Law and Human Rights. Farnham: Ashgate Publishing, 2009.

HERZ, M. Política de segurança dos EUA para a América Latina após o final da Guerra Fria. Estudos Avançados, v. 16, n. 46, p. 85-104, 2002. Disponível em: < http://www.scielo.br/scielo.php?pid=S0103-40142002000300007\&script=sci_arttext> Acesso em 18 jun. 2015.

JAEGER, Bruna Coelho. Crise e colapso da Unasul: o desmantelamento da integração sul-americana em tempos de ofensiva conservadora. Conjuntura Austral: journal of the global South, v. 10. n. 49, p 5-12, 2019. Disponível em: <http://seer.ufrgs.br/ConjunturaAustral/article/view/88358>. Acesso em 18 jun. 2015.

KRASKA, P. Militarization and policing-Its relevance to 21st century police. Policing: a journal of policy and practice, v. 1, n. 4, p. 501-513, 2007.

LÓPEZ, Ernesto. Atajar la sudestada. In: WINAND, É.; AGUILAR, S.; RODRIGUES, T. (Eds.). Defesa e Segurança do Atlântico Sul. São Cristovão - SE: Editora UFS, 2016. v. 1p. 269.

LÓPEZ, Ernesto. Seguridad Nacional y Cedición Militar. Buenos Aires: Legasa, 1987.

LYRA, Mariana. P. O.. Plano Colômbia e Iniciativa Mérida: uma análise à luz da Segurança Humana. Argumentum, Vitória (ES), v. 6, n.2, p. 64-75, jul./dez. 2014.

MATHIAS, S. K. Distensão no Brasil: o projeto militar (1973-1979). Campinas: Papirus, 1995.

MATHIAS, S. K.; CAMPOS, B. S.; SANTOS, L. F. S. Política militar del Gobierno de Rousseff: reflexiones sobre la actuación de las Fuerzas Armadas en las UPP y la MINUSTAH. Íconos. Revista de Ciencias Sociales, n. 55, p. 115-138, 2016.

MATHIAS, S. K.; GUZZI, A. C. Autonomia na Lei: as Forças Armadas nas constituições nacionais. Revista Brasileira de Ciências Sociais, v. 25, n. 73, p. 41-57, 2010.

MATHIAS, S. K.; SOARES, S. A. (EDS.). Novas ameaças: dimensões e perspectivas. São Paulo: Sicurezza, 2003.

MARMO, Marinella; CHAZAL, Nerida. Transnational Crime and Criminal Justice. SAGE Publications Ltd. Los Angeles | London | New Delhi | Singapore | Washington DC | Melbourne. 2016.

MCCANN, F. D. Soldados da Pátria: História do Exército Brasileiro 1889-1937. São Paulo: Companhia das Letras, 2007.

MEARSHEIMER, JOHN. The tragedy of great power politics. New York: W. W. Norton \& Company, 2001.

ORGANIZAÇÃO DAS NAÇÕES UNIDAS (ONU). Conferência das Nações Unidas Contra o Crime Organizado. $\quad 2000.2$ Dalermo, em: 
<http://www.unodc.org/pdf/crime/a_res_55/res5525e.pdf>. Acesso em 31 jul. 2019.

OLIVEIRA, E. R. De Geisel a Collor: Forças Armadas, Transição e Democracia. Campinas: Papirus Editora, 1994.

ORGANIZAÇÃO DOS ESTADOS AMERICANOS. Declaração sobre segurança nas Américas. Cidade do México, 2003. Disponível em <http://www.oas.org/juridico/portuguese/decl_security_pt.pdf>. Acesso em 15 nov. 2017.

ORGANIZAÇÃO DOS ESTADOS AMERICANOS. Inter-American Drug Abuse Control Commission (CICAD), 2013. Disponível em: <http://www.cicad.oas.org/Main/Template.asp?File=/Main/AboutCICAD/about_eng.asp>. Acesso em 6 jul. 2015.

PASSOS, A. M. Fighting crime and maintaining order: shared worldviews of civilian and military elites in Brazil and Mexico. Third World Quarterly, v. 39, n. 2, p. 314-330, 2018.

PEARCE, J. Perverse state formation and securitized democracy in Latin America. New Patterns of Militarized Violence and Coercion in the Americas, v. 17, n. 2, p. 286-306, 2010.

PEREIRA, Paulo. Os Estados Unidos e a ameaça do crime organizado transnacional nos anos 1990. Revista Brasileira de Política Internacional, v. 58, n. 1, p. 84-107, 2015.

PEREIRA, Paulo. Securitização do Crime Organizado Transnacional nos Estados Unidos na década de 1990. Tese (doutorado) - Universidade Estadual de Campinas, Instituto de Filosofia e Ciências Humanas. Campinas (s.n.), 2011.

REITANO, T.; LUGO, L. B. R.-B. DE; JESPERSON, S. (EDS.). Militarised Responses to Transnational Organised Crime: the war on crime. [s.l.] Palgrave Macmillan, 2017.

RODRIGUES, Thiago. Narcotráfico e militarização nas Américas: vício de guerra. Contexto Internacional, v. 34, n. 1, p. 9-41, 2012b. Disponível em <http://www.scielo.br/pdf/cint/v34n1/v34n1a01.pdf>. Acesso em 10 nov. 2015.

RODRIGUES, Thiago. Narcotráfico: uma guerra na guerra. 2.ed. São Paulo: Desatino, 2012a. 144p.

RODRIGUES, Thiago. Política e drogas nas Américas. São Paulo: EDUC:FAPESP, 2004, 334p.

ROUQUIÉ, A. O Estado militar na América Latina. São Paulo: Alfa-Omega, 1984. v. 16

SAINT-PIERRE, Héctor L. Breve reflexión sobre el empleo de las Fuerzas Armadas. Voces en el Fénix, v. 48, 2015.

SAINT-PIERRE, Héctor L. "Defesa" ou "Segurança"? Reflexões em torno de conceitos e ideologias. Contexto Internacional, v. 33, n. 2, p. 407-433, 2011.

SAINT-PIERRE, Héctor L. El concepto de la seguridad multidemensional: una aproximación crítica. In: MEJÍAS, S.; RICAURTE, V. (Eds.). El concepto y las relaciones multilaterales de seguridad y defensa en el contexto de la UNASUR. Madrid: Instituto Universitario General Gutiérrez Mellado, 2012.

SCHULTZE-KRAFT, Markus. Actualización y ampliación de los mapeos sobre el crimen organizado en Colombia y la región andina, 2008-2009. In: MATHIEU, H; GUARNIZO. C. N (Eds.). Anuario 2010 de la Seguridad Regional en América Latina y el Caribe. Bogotá, oct. 2010.

SECRETARIA NACIONAL DE POLÍTICAS SOBRE DROGAS. Legislação e políticas públicas sobre drogas no Brasil. Brasília: Ministério da Justiça, Secretaria Nacional de Políticas sobre Drogas, 2011. 
SILVA, Luiza. L. A Questão das Drogas nas Relações Internacionais: uma perspectiva brasileira. Brasília: Fundação Alexandre de Gusmão, 2013.

SOARES, S. A. Controles e autonomias: as Forças Armadas e sistema político brasileiro (1974-1999). 1. ed. São Paulo: Editora Unesp, 2006.

SOARES, S. A. Forças armadas e segurança pública: a construção do padrão de emprego militar na argentina e no brasil entre 2005 e 2015. São Paulo: Programa de Pós-Graduação em Relações Internacionais San Tiago Dantas (UNESP-UNICAMP-PUC-SP), 2018.

SOUZA, A. B. DE. Mito de Estado, Estado é: Duque de Caxias e as práticas pacificadoras do Exército Imperial. In: Pacificar o Brasil: das guerras justas às UPPs. São Paulo: Alameda Casa Editorial, 2017. p. $175-195$.

THOMPSON, J.Mercenaries, pirates and sovereigns : state-building and extraterritorial violence in early modern Europe. Princeton: Princeton University Press, 1994.

UNIÃO DAS NAÇÕES SUL-AMERICANAS. Estatuto del Consejo Suramericano sobre el Problema Mundial de las Drogas. Quito, Ecuador. Abril 2010. Disponível em <http://www.unasursg.org/images/descargas/ESTATUTOS\%20CONSEJOS\%20MINISTERIALES\%20 SECTORIALES/ESTATUTO\%20CONSEJO\%20DE\%20DROGAS.pdf>. Acesso em 8 maio 2015.

UNIÓN DE LAS NACIONES SURAMERICANAS. Acta de La VI Reunion del Consejo Suramericano Sobre el Problema Mundial de las Drogas (CSPMD) de la UNIÓN DE NACIONES SURAMERICANAS (UNASUR). Presidencia Pro Tempore Argentina (2017-2018). Buenos Aires, 09 de febrero de 2018. Disponível em <http:/www.iri.edu.ar/wp-content/uploads/2018/04/bo-alatina.63-unasuractaproblemamundialdrogas.pdf $>$. Acesso em 3 nov. 2019.

UNIÓN DE LAS NACIONES SURAMERICANAS. Centro de Estudios Estratégicos de Defensa. Relatório Preliminar do CEED ao Conselho de Defesa Sulamericano sobre os termos de referência para os conceitos de segurança e defesa na região sul-americana. Buenos Aires, 2012. Disponível em <http://ceed.unasursg.org/Portugues/09-Downloads/Biblioteca/SEGURIDADDEFENSA-PORT.pdf>. Acesso em 15 nov. 2017.

UNITED STATES. The White House. National Security Directive Number 221: Narcotics and National Security. Washington, April 8, 1986. Disponível em <http://fas.org/irp/offdocs/nsdd/nsdd221.pdf>. Acesso em 12 jul. 2015.

UNITED STATES. The White House. Presidential Decision Directive/NSC-42: International Organized Crime. Washington, October 21, 1995. Disponível em<https://fas.org/irp/offdocs/pdd/pdd-42.pdf>. Acesso em 12 jul. 2015.

VELASCO, C. A. El Consejo Suramericano sobre el Problema Mundial de las Drogas de la UNASUR. Logros y desafios 2012-2013. Consorcio Internacional sobre Políticas de Drogas, marzo 2013.

VIGGIANO, Juliana. COOPERAÇÃO REGIONAL NA SEGURANÇA PÚBLICA: AVALIAÇÃO DO QUADRO NORMATIVO NO CONTEXTO DA UNASUL. AUSTRAL: Brazilian Journal of Strategy \& International Relations, $\quad$ v. $\quad 7, \quad$ n. $14 . \quad$ Disponível em <https://www.seer.ufrgs.br/austral/article/view/87986>. Acesso em 03 nov. 2019.

VILLA. R.. A securitização, o overlapping das guerras às drogas e ao terror, na agenda de segurança dos Estados Unidos: caso Colômbia. In:. NASSER R. M (Org.). Os conflitos internacionais em múltiplas dimensões. São Paulo, Unesp, 2009, p.191-201.

VILLA, R.; OSTOS, M. P. As relações Colômbia, países vizinhos e Estados Unidos: visões em torno da agenda de segurança. Revista Brasileira de Política Internacional, v. 48, n. 2, p. 86-110, 2005. Disponível em <http://www.scielo.br/pdf/rbpi/v48n2/a05v48n2.pdf>. Acesso em 10 nov. 2015. 
WOODIWISS, M. Transnational organised crime: The global reach of an American concept. In: Edwards, A.and Gill, P., eds. (2003) Transnational Organised Crime: Perspectives on Global Security. Routledge, 2003, pp. 13-27.

ZABYELINA, Yuliya. Transnational organized crime in International Relations. Central European Journal of International \& Security Studies, v. 3, n. 1, 2009.

ZAVERUCCHA, J. FHC, forças armadas e polícia: entre o autoritarismo e a democracia (1999-2002). Rio de Janeiro: Editora Record, 2005.

WALTZ, Kenneth. Teoria das Relações Internacionais. Lisboa: Gradiva, 2002.

WEBER, M. Economia y Sociedad: Esbozos de sociología comprensiva. México: Fondo de Cultura Económica, 2002.

WEISS, T. The blurring border between the police and the military: A debate without foundations. Cooperation and Conflict, v. 46, n. 3, p. 396-405, 2011. 


\section{RESUMO}

A área de Relações Internacionais constituiu-se por meio da divisão teórica entre o doméstico pacificado e o internacional anárquico. Os Estados, enquanto agentes soberanos, possuiriam o monopólio legítimo da força dentro de suas fronteiras, ao passo que lutariam por sua sobrevivência no sistema internacional. No entanto, certas dinâmicas e atores desafiam essa divisão. O objetivo neste artigo é analisar como a construção política do crime organizado transnacional como uma ameaça e a definição dos meios de força empregados para combatê-lo, em especial as Forças Armadas, rompem com a divisão entre o doméstico e o internacional. Ao discorrer sobre o caso do combate ao tráfico de drogas no Brasil, compreende-se que a definição de tal atividade como uma ameaça no país foi o resultado de um processo de expansão e internacionalização da política de "guerra às drogas", iniciado pelo governo estadunidense. A definição do crime não ficou, portanto, limitada à territorialidade de um Estado. Paralelamente, o emprego das forças armadas no combate da criminalidade interna, recorrente na história do Brasil, demonstra que divisão teórica em questão representa um princípio normativo e não a descrição de um padrão histórico.

Palavras-chave: Crime Organizado Transnacional; Forças Armadas; Brasil.

\section{ABSTRACT}

The International Relations field constituted itself through the theoretical division between a pacified domestic sphere and an anarchic international system. States, as sovereign actors, are understood to have the legitimate monopoly of force within their borders, while struggle to survive in the international realm. However, certain dynamics and actors challenge this division. This paper aims to show how the political construction of transnational organized crime as a threat and the definition of the means of force employed to combat it, especially the armed forces, break with the sharp division between domestic and international. In discussing the case of combating drug trafficking in Brazil, it is understood that the definition of such activity as a threat results from a process of expansion and internationalization of the "war on drugs" policy, fostered by the United States government. The definition of crime was therefore not limited to the territoriality of the Brazilian state. At the same time, the deployment of the armed forces to combat internal crime, which is recurrent in Brazilian history, demonstrates that the theoretical division in question represents a normative principle and not a description of a historical pattern.

Key-words: Transnational Organized Crime; Armed Forces; Brazil.

\section{COPYRIGHT:}

Este é um artigo publicado em acesso aberto e distribuído sob os termos da Licença de Atribuição Creative Commons, que permite uso irrestrito, distribuição e reprodução em qualquer meio, desde que o autor e a fonte originais sejam creditados.

This is an open-access article distributed under the terms of a Creative Commons Attribution License, which permits unrestricted use, distribution, and reproduction in any medium, provided that the original author and source are credited.

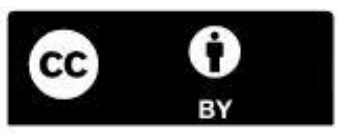

